\title{
Superação de dormência em sementes de Gleditschia amorphoides Taub.
}

\author{
Overcoming of seed dormancy in Gleditschia amorphoides Taub.
}

\section{Michele Fernanda Bortolini ${ }^{I}$ Henrique Soares KoehlerII Katia Christina Zuffellato-Ribas ${ }^{\text {II }}$ Marlene De Matos Malavasi ${ }^{\mathrm{IV}}$ Andréa Maria Teixeira Fortes ${ }^{\mathrm{V}}$}

\begin{abstract}
- NOTA -
RESUMO

O trabalho teve como objetivo avaliar métodos para a superação da dormência de sementes de sucará. As sementes receberam os seguintes tratamentos: 1) testemunha; 2) escarificação mecânica; 3) escarificação mecânica + águal $24 h$; 4) escarificação mecânica +água quente/24h; 5) água quente/24h; 6) ácido sulfúrico $\left.\left.\left(\mathrm{H}_{2} \mathrm{SO}_{4}\right) / 1 \mathrm{~h} ; 7\right) \mathrm{H}_{2} \mathrm{SO}_{4} / 2 \mathrm{~h} ; 8\right)$ $\mathrm{H}_{2} \mathrm{SO}_{4} / \mathrm{lh}+$ água/24h; 9) $\mathrm{H}_{2} \mathrm{SO}_{4} / 30 \mathrm{~min}+$ água corrente/4h; 10) escarificação mecânica + água corrente/4h. O teste de germinação foi conduzido em rolos de papel Germitest acondicionados em câmara de germinação, à $25^{\circ} \mathrm{C}$, com fotoperíodo de $12 \mathrm{~h}$ por 26 dias. Avaliou-se também o tempo e a velocidade média de germinação. $O$ delineamento experimental foi inteiramente casualizado, com quatro

3) mechanical scarfication + water/24h; 4) mechanical scarfication + hot water/24h;5) hot water/24h; 6) sulfuric acid $\left(\mathrm{H}_{2} \mathrm{SO}_{4}\right) / \mathrm{lh}$; 7) $\mathrm{H}_{2} \mathrm{SO}_{4} / 2 \mathrm{~h}$;8) $\mathrm{H}_{2} \mathrm{SO}_{4} / \mathrm{lh}+$ water/24h; 9) $\mathrm{H}_{2} \mathrm{SO}_{4} /$ 30 min + flowing water/4h; 10) mechanical scarfication + flowing water/4h. Germination was done in rolls of Germitest conditioned in a germination chamber under $25^{\circ} \mathrm{C}$, during $12 \mathrm{~h}$ for 26 days. Percentage, time and average speed of germination were evaluated. The experimental design was completely casual with 10 treatments, 4 repetitions and 25 seeds. The best results were recorded for treatments with mechanical and chemical scarification with averages between 76 and $98 \%$ of germination, from 2.17 to 2.88 days for medium time for germination and 0.46 to 0.48 seeds/day for average speed of germination, demonstrating that these are the best methods to overcome dormancy of seeds.
\end{abstract} repetições de 25 sementes. O melhor desempenho germinativo foi registrado para as sementes submetidas à escarificação mecânica e química, com médias entre 76 e $98 \%$ de germinação, respectivamente, 2,17 a 2,88 dias para tempo médio de germinação e 0,46 a 0,47 sementes/dia para velocidade média de germinação, demonstrando serem estes os melhores métodos para superação da dormência de sementes dessa espécie.

Palavras-chave: sucará, germinação, espécie nativa.

\section{ABSTRACT}

The objective of this research was to evaluate methods to overcome dormancy of seeds of Gleditschia amorphoides. For dormancy's overcoming the seeds received the following treatments: 1) control; 2) mechanical scarfication
Key words: sucará, germination, native specie.

Gleditschia amorphoides Taub. (Fabaceae), popularmente conhecida como sucará, é uma espécie utilizada para recuperação de florestas ribeirinhas e, como a maioria das sementes de leguminosas, há problemas de dormência imposta pelo tegumento, sendo que a estrutura e/ou a composição deste, impedem a entrada de água, bloqueando o início da germinação (MARCOS FILHO, 2005).

Para os viveiristas, o mecanismo de dormência se torna uma desvantagem, induzindo

'Centro de Ciências, Tecnologia e Produção, Pontifica Universidade Católica do Paraná (PUCPR), 85902-532, Toledo, PR, Brasil. E-mail: mibortolini@hotmail.com. Autor para correspondência.

"Departamento Fitotecnia e Fitossanitarismo, Setor de Ciências Agrárias, Universidade Federal do Paraná (UFPR), Curitiba, PR, Brasil.

"'Departamento Botânica, Setor de Ciências Biológicas, UFPR, Curitiba, PR, Brasil.

${ }^{\mathrm{IV}}$ Centro de Ciências Agrárias, Universidade Estadual do Oeste do Paraná (UNIOESTE), Marechal Cândido Rondon, PR, Brasil.

${ }^{\vee}$ Centro de Ciências Biológicas e da Saúde, UNIOESTE, Cascavel, PR, Brasil. 
grande desuniformidade entre as mudas e perda das sementes por deterioração, uma vez que permanecem mais tempo no solo antes da germinação (SMIDERLE et al., 2005). O estudo de metodologias que melhorem a germinação e o desempenho das mudas no viveiro é importante para acelerare uniformizar o estabelecimento inicial das plantas no campo (ROVERSI et al., 2002).

Para que ocorra a germinação dessas sementes dormentes, procura-se romper ou enfraquecer o tegumento, processo conhecido por escarificação. Em condições de laboratório, vários são os métodos utilizados para a superação desse tipo de dormência, como a embebição em água, a escarificação mecânica e química, comumente utilizando ácido sulfúrico (BRASIL, 2009). Segundo EIRA et al. (1993), os tratamentos utilizados na superação da dormência podem ter vantagens e desvantagens, de modo que cada um deve ser testado. Assim, o objetivo deste trabalho foi avaliar metodologias para a superação da dormência de sementes de Gleditschia amorphoides Taub.

As sementes foram colhidas em $2006 \mathrm{em}$ Santa Helena - PR, sendo o trabalho realizado no Laboratório de Tecnologia de Sementes da UNIOESTE. $\mathrm{O}$ lote de sementes foi inicialmente avaliado com a determinação da massa de mil sementes e do grau de umidade, seguindo metodologias adaptadas de FOGAÇA (2000) e BRASIL (2009). Para a curva de absorção de água, foram utilizadas três repetições de cinco gramas para sementes intactas e para sementes escarificadas com lixa de papel n.120, que foram imersas em água destilada, à temperatura constante de $25^{\circ} \mathrm{C}$ por 72 horas com aeração. A pesagem das sementes foi realizada em intervalos de duas horas nas primeiras 36 horas de embebição, de quatro horas por mais 12 horas e de seis horas até completar 72 horas. Os resultados foram expressos em porcentagem de aumento de peso, em relação à massa da matéria fresca inicial.

Sementes de G amorphoides Taub. foram submetidas aos seguintes tratamentos para a superação da dormência: testemunha (sem tratamento); escarificação mecânica (uso de lixa de papel n.120, na região oposta à micrópila até o início da exposição do endosperma); escarificação mecânica seguida de embebição em água à temperatura ambiente, por 24h; escarificação mecânica seguida de embebição em água inicialmente fervente, sendo mantidas por $24 \mathrm{~h}$ em temperatura ambiente; embebição em água inicialmente fervente, por $24 \mathrm{~h}$ em temperatura ambiente; escarificação química (imersão em ácido sulfúrico PA por $1 \mathrm{~h}$ ); escarificação química por $2 \mathrm{~h}$; escarificação química por $1 \mathrm{~h}$, seguida de embebição em água à temperatura ambiente por $24 \mathrm{~h}$; escarificação química por 30min, seguida de lavagem em água corrente por 4h; escarificação mecânica seguida de lavagem em água corrente por $4 \mathrm{~h}$.

O teste de germinação foi realizado em rolos de papel Germitest, umedecidos com água destilada na proporção de 2,5 vezes a sua massa seca e acondicionados em câmara de germinação, à temperatura constante de $25^{\circ} \mathrm{C}$, sob fotoperíodo de 12 horas. Foram realizadas contagens diárias das sementes germinadas, até a sua estabilização (26 dias), considerando-se germinadas aquelas com comprimento de raiz igual ou superior a $2 \mathrm{~mm}$ (HADAS, 1976). As variáveis analisadas foram: porcentagem de germinação, tempo médio e velocidade média de germinação, calculados segundo LABOURIAU (1983). $\mathrm{O}$ delineamento experimental foi inteiramente casualizado, com quatro repetições de 25 sementes para cada tratamento. Os dados foram submetidos à análise de variância (teste F) e as médias comparadas pelo teste de Tukey, a 5\% de probabilidade.

Como resultados, foram encontrados para a massa de mil sementes aproximadamente $253 \mathrm{~g}$. A umidade do lote das sementes foi de $9,9 \%$, sendo, portanto, classificada como ortodoxa, podendo atingir níveis de umidade próximos a $15,0 \%$ sem perder sua viabilidade (BASKIN \& BASKIN, 1998).

Pelos dados da figura 1, é possível visualizar a diferença na porcentagem de aumento de peso entre sementes intactas e escarificadas durante o processo de embebição, uma vez que depois de 72 horas foi possível constatar que as sementes intactas praticamente não alteraram seu teor de água. Para as sementes escarificadas mecanicamente, constatou-se um incremento de $150 \%$ em relação ao peso inicial, evidenciando, dessa forma, a impermeabilidade do tegumento à água.

Caesalpinea ferrea Mart. (Benth.) (pauferro), Cassia grandis L. (cássia grande) e Samanea saman Merrill (sama), todas da família Fabaceae, também tiveram aumento acentuado no peso durante a embebição, quando escarificadas e, segundo LOPES et al. (1998), esse tipo de tratamento pode promover a ruptura da adesão entre as células da epiderme do tegumento, permitindo assim a hidratação.

Dentre os tratamentos empregados para superar a dormência, destacou-se a escarificação química por uma e duas horas e a escarificação química por uma hora seguida de embebição, com porcentagem de germinação de 96,98 e $85 \%$, respectivamente, estatisticamente igual entre si e superiores aos demais tratamentos avaliados. Para os tratamentos com escarificação mecânica, escarificação mecânica seguida de embebição e escarificação mecânica com embebição 


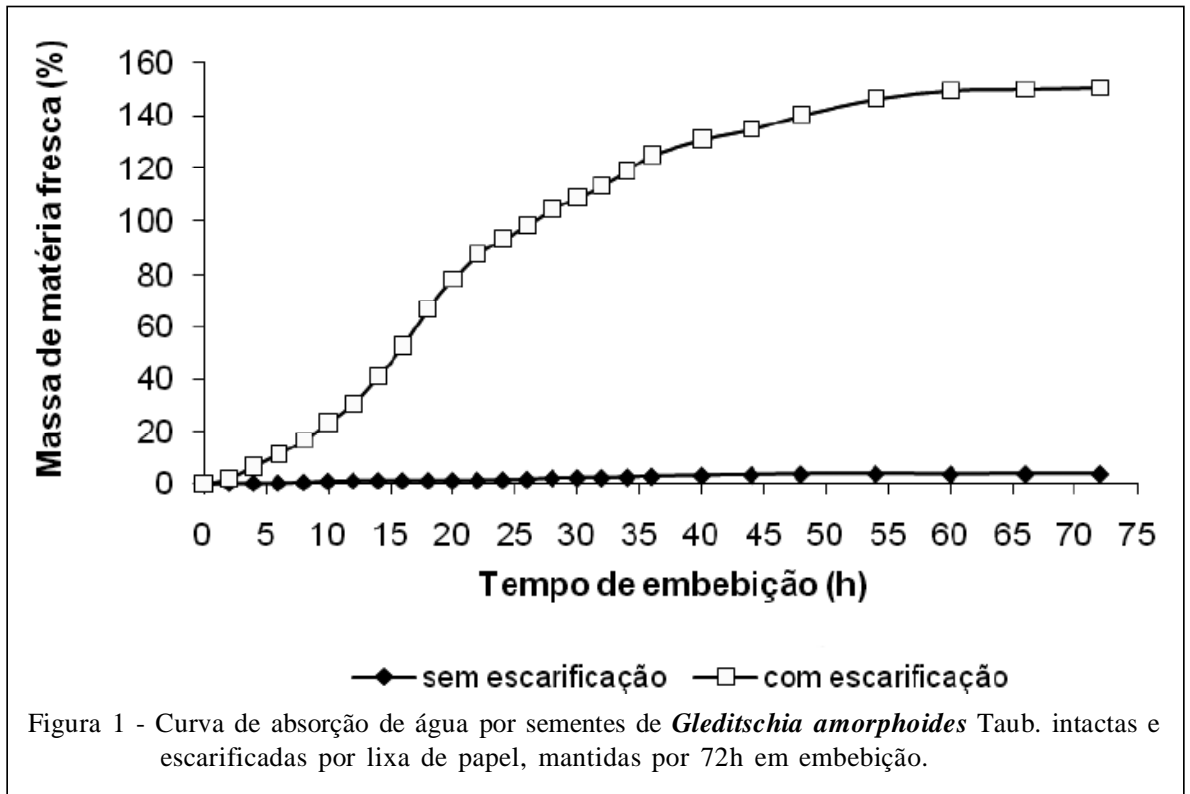

em água inicialmente fervente, as médias foram de 84, 76 e $79 \%$, respectivamente, estes com porcentagens de germinação estatisticamente iguais entre si e superiores à testemunha (Tabela 1). Esses resultados concordam com FOGAÇA (2000) que, trabalhando com sementes de Gleditschia amorphoides Taub., também encontrou os melhores valores para a germinação em tratamentos de escarificação mecânica e química (97 e $92 \%$, respectivamente).

A germinação de sementes de Gleditsia triacanthos Linn. (acácia negra), quando submetidas a ácido sulfúrico por 30 minutos, foi de 77\% (SHEIKH, 1977). SINGH et al., (1991) também utilizando o ácido sulfúrico, constataram $93 \%$ de germinação em sementes de $\boldsymbol{G}$ triacanthos Linn., resultados que corroboram com os obtidos no presente trabalho com $\boldsymbol{G}$. amorphoides Taub.

O uso do ácido sulfúrico, devido à ação abrasiva, pode ter rompido as camadas de macroesclereídes ou a deposição de suberina presente no tegumento das sementes de $\boldsymbol{G}$ amorphoides Taub., como indicado por MAYER \& POLJAKOFF-MAYBER (1978), assim, com o rompimento da barreira à entrada de água, houve embebição e, consequentemente, germinação.

Para a variável tempo médio de germinação, destacaram-se os tratamentos de escarificação mecânica seguida de embebição por $24 \mathrm{~h}$, registrandose 2,17 e 2,11 (dias), resultado que não diferiu estatisticamente dos tratamentos com escarificação química e mecânica com lavagem, estes com 2,62, 2,75 e 2,88, respectivamente. Esses resultados foram semelhantes aos observados para a velocidade média de germinação, sendo 0,46 e 0,47 (sementes/dia) para as sementes com escarificação mecânica e embebição, os quais não diferiram entre si (Tabela 1).

Os resultados encontrados no presente trabalho demonstraram que além da escarificação mecânica, método com eficiência já registrada (PATANÈ \& GRESTA, 2006), a permanência das sementes em embebição por $24 \mathrm{~h}$ pode acelerar o início da germinação, pois a absorção de água representa o passo inicial do processo germinativo (FERREIRA \& GENTIL, 2006).

Apesar de ser um método vantajoso, de baixo custo e eficiente para superar a dormência de sementes de algumas leguminosas, a imersão em água inicialmente fervente não foi efetiva para as sementes de $\boldsymbol{G}$. amorphoides Taub. (43\% de germinação), não diferindo estatisticamente da testemunha (Tabela 1). Para sementes de $\boldsymbol{G}$ triacanthos Linn., também imersas em água quente, os resultados foram semelhantes, $46 \%$ de germinação (SINGH et al., 1991). Provavelmente, a imersão em água inicialmente fervente não tenha sido suficiente para romper as barreiras no tegumento e, assim, não ocorreu com sucesso o processo de embebição, prejudicando a germinação destas.

A porcentagem de germinação das sementes de $\boldsymbol{G}$. amorphoides Taub., submetidas à escarificação mecânica seguida por lavagem em água corrente por quatro horas, não diferiu estatisticamente dos demais tratamentos com escarificação mecânica, sugerindo que possivelmente essas sementes não apresentam inibidores químicos no tegumento. A presença de 
Tabela 1 - Germinação, tempo médio de germinação e velocidade média de germinação de sementes de Gleditschia amorphoides, submetidas a tratamentos para superar a dormência.

\begin{tabular}{lccc}
\hline Tratamentos & Germinação $(\%)^{*}$ & Tempo médio (dias)* $^{*}$ & Velocidade média (sementes dia $\left.^{-1}\right)$ \\
\hline Testemunha & $29 \mathrm{e}$ & $18,11 \mathrm{~d}$ & $0,06 \mathrm{~g}$ \\
Escarificação mecânica & $84 \mathrm{bc}$ & $3,73 \mathrm{~b}$ & $0,27 \mathrm{def}$ \\
Esc. mec. + embebição & $76 \mathrm{c}$ & $2,17 \mathrm{a}$ & $0,46 \mathrm{ab}$ \\
Esc. mec. + embe. água fervente & $79 \mathrm{bc}$ & $2,11 \mathrm{a}$ & $0,47 \mathrm{a}$ \\
Embebição em água fervente & $43 \mathrm{de}$ & $15,81 \mathrm{~d}$ & $0,06 \mathrm{~g}$ \\
Escarificação química 1h & $96 \mathrm{ab}$ & $3,58 \mathrm{~b}$ & $0,27 \mathrm{ef}$ \\
Escarificação química 2h & $98 \mathrm{a}$ & $2,62 \mathrm{ab}$ & $0,35 \mathrm{~cd}$ \\
Esc. química 1h + embebição & $85 \mathrm{abc}$ & $2,75 \mathrm{ab}$ & $0,37 \mathrm{bc}$ \\
Esc. química 30min + lavagem & $65 \mathrm{~cd}$ & $6,00 \mathrm{c}$ & $0,18 \mathrm{f}$ \\
Esc. mecânica + lavagem & $67 \mathrm{~cd}$ & $2,88 \mathrm{ab}$ & $0,35 \mathrm{cde}$ \\
CV\% & 24,16 & 5,75 & 9,08 \\
\hline
\end{tabular}

$\mathrm{CV}=$ Coeficiente de variação. *Dados transformados por arco seno $\sqrt{X} / 100$ e $\sqrt{X}$, respectivamente. Médias seguidas da mesma letra na coluna não diferem estatisticamente entre si pelo teste de Tukey, em nível de 5\% de probabilidade.

lactonas, cumarinas, terpenóides, $\mathrm{ABA}$, entre outros, podem impedir o livre acesso do oxigênio ao embrião ou ainda a liberação de gás carbônico (MARCOS FILHO, 2005).

Pelos resultados, constatou-se que o potencial germinativo das sementes de $\boldsymbol{G}$ amorphoides Taub. foi maior quando submetidas à escarificação mecânica e química. Apesar do manuseio com ácido sulfúrico ser perigoso, este tratamento se torna mais prático do que a escarificação mecânica (OLIVEIRA et al., 2003). Portanto, com a utilização de tratamentos para a superação da dormência de sementes de $\boldsymbol{G}$. amorphoides Taub., foi possível aumentar a porcentagem em cerca de $70 \%$ e diminuir o tempo de germinação em 15 dias. Assim, é possível evitar a desuniformidade entre as futuras mudas e a perda das sementes no campo. Dessa forma, a escarificação mecânica com lixa seguida de embebição e escarificação química com ácido sulfúrico por uma ou duas horas são os melhores métodos para superação da dormência de sementes de G. amorphoides Taub.

\section{REFERÊNCIAS}

BASKIN, C.C.; BASKIN, J.M. Seeds ecology, biogeography, and evolution of dormancy and germination. California: Academic, 1998. 666p.

BRASIL, Ministério da Agricultura, Pecuária e Abastecimento. Regras para análise de sementes. Brasília: SNDA/DNDV/ CLAV, 2009. 395p.

EIRA, M.T.S. et al. Superação da dormência de sementes de Enterolobium contortisiliquum (Vell.) Morong. - Leguminosa. Revista Brasileira de Sementes, Brasília, v.15, n.2, p.176$181,1993$.
FERREIRA, S.A.N.; GENTIL, D.F.O. Extração, embebição e germinação de sementes de tucumã (Astrocaryum aculeatum). Acta Amazonica, Manaus, v.36, n.2, p.141146, 2006. Disponível em: <http://acta.inpa.gov.br/ sumarios.php? opcao $=$ sumario $\&$ volume $=36 \&$ edicao $=2>$. Acesso em: 03 mar. 2011.

FOGAÇA, C.A. Padronização e adequação de metodologias para avaliação da qualidade física e fisiológica de sementes de Gleditschia amorphoides Taub. Caesalpinaceae. 2000. 94f. Trabalho de conclusão de curso (Graduação em Agronomia) - Universidade Estadual do Oeste do Paraná, Marechal Cândido Rondon, PR.

HADAS, A. Water uptake and germination of leguminous seeds under changing external water potential in osmotic solution. Journal of Experimental Botany, Oxford, v.27, n.98, p.480489, 1976.

LABOURIAU, L.G. A germinação de sementes. Washington: Organização dos Estados Americanos, 1983. 174p.

LOPES, J.C. et al. Germinação de sementes de espécies florestais de Caesalpinea ferrea Mart. Ex Tul. var. leiostachya Benth., Cassia grandis L. e Samanea saman Merril. após tratamentos para superar a dormência. Revista Brasileira de sementes, Londrina, v.20, n.1, p.80-86, 1998.

MARCOS FILHO, J. Fisiologia de sementes de plantas cultivadas. Piracicaba: FEALQ, 2005. 495p.

MAYER, A.M.; POLJAKOFF-MAYBER, A. The germination of seeds. 2.ed. Frankfurt: Pergamon, 1978. 191p.

OLIVEIRA, L.M. et al. Avaliação de métodos para quebra de dormência e para a desinfestação de sementes de canafístula (Peltophorum dubium Sprengel.Taubert.). Revista Árvore, Viçosa, v.27, n.5, p.597-603, 2003. Disponível em: <http:// www.scielo.br/scielo.php? script $=$ sci_issuetoc\&pid $=$ $0100676220030005 \& \operatorname{lng}=$ en $\& n r m=i s o>$. Acesso em: 03 mar. 2011. doi: 10.1590/S0100-67622003000500001. 
PATANÈ, C.; GRESTA, F. Germination of Astragalus hamosus and Medicago orbicularis as affected by seed-coat dormancy breaking techniques. Journal of Arid Environments, London. v.67, n.1, p.165-173, 2006.

ROVERSI, T. et al. Superação de dormência em sementes de acácia negra (Acacia mearnsii Willd.). Revista Brasileira de Agrociência, Pelotas, v.8, n.2, p.161-163, 2002. Disponível em: 〈http://www.ufpel.tche.br/faem/agrociencia/v8n2.htm>. Acesso em: 03 mar. 2011.

SMIDERLE, O.J. et al. Tratamentos pré-germinativos em sementes de acácia. Revista Brasileira de Sementes, Brasília, v.27, n.1, p.78-85, 2005. Disponível em: <http://www.scielo.br/ scielo.php?script=sci_issuetoc\&pid $=0101312220050001 \& \operatorname{lng}=$ =en\&nrm=iso $>$. Acesso em: 03 mar. 2011. doi: 10.1590/S010131222005000100010 .

SHEIKH, M.I. H SO treatment helps early germination of Gleditsia triacanthos seed. Pakistan Journal of Forestry, Peshawar, v.27, n.4, p.218-219, 1977.

SINGH, D.P. et al. An evaluation of scarification methods for seeds of two leguminous trees. New Forests, Dordrecht. n.5, p.139-145, 1991. 